\title{
Anabases
}

ANABASES Traditions et réceptions de l'Antiquité

$26 \mid 2017$

Varia

\section{Ayelet H. LUSHKOV, Magistracy and the Historiography of the Roman Republic. Politics in Prose}

Cyrielle Landrea

\section{OpenEdition}

\section{Journals}

Édition électronique

URL : http://journals.openedition.org/anabases/6264

DOI : 10.4000/anabases.6264

ISSN : 2256-9421

\section{Éditeur}

E.R.A.S.M.E.

\section{Édition imprimée}

Date de publication : 1 novembre 2017

Pagination : 240-241

ISSN : 1774-4296

\section{Référence électronique}

Cyrielle Landrea, «Ayelet H. Lushrov, Magistracy and the Historiography of the Roman Republic. Politics in

Prose », Anabases [En ligne], 26 | 2017, mis en ligne le 01 novembre 2017, consulté le 20 janvier 2021

URL : http://journals.openedition.org/anabases/6264; DOI : https://doi.org/10.4000/anabases.6264

Ce document a été généré automatiquement le 20 janvier 2021.

(c) Anabases 


\title{
Ayelet H. LUSHKOV, Magistracy and the Historiography of the Roman Republic. Politics in Prose
}

\author{
Cyrielle Landrea
}

\section{RÉFÉRENCE}

Ayelet H. LUSHKov, Magistracy and the Historiography of the Roman Republic. Politics in Prose, Cambridge, Cambridge University Press, 2015, 214 p., 67 livres / ISBN 9781107040908.

1 La culture des exempla est au cœur des pratiques mémorielles romaines, puisque les grands personnages font pleinement partie de la mémoire collective. Pourtant l'étude des magistrats romains a souvent été abordée par le biais d'études constitutionnelles et prosopographiques. A contrario l'auteur opte pour une approche plus littéraire qu'historique, en utilisant les œuvres de Cicéron, de Salluste, mais surtout de Tite-Live. Les $\mathrm{A} b$ Vrbe condita libri offrent effectivement une multitude d'exempla. En étudiant les anecdotes historiques et les exempla, A. Lushkov met en exergue les comportements politiques à l'époque républicaine en les replaçant dans un débat historiographique. Les magistratures sont alors analysées comme un phénomène textuel de la culture politique et apparaissent comme un paradigme heuristique permettant d'étudier des réalités tant politiques que littéraires. Un des enjeux est ensuite de montrer la valeur didactique de l'exemplum. En outre l'exemplum invite également le lecteur à s'interroger sur les conditions de la production littéraire et les conséquences de cette évaluation dans un contexte aussi politique. La définition retenue de l'exemplum est finalement classique, puisqu'il s'agit de celle de J. Chaplin : «anything from the past that serves as a guide to conduct within the text» (p. 3).

2 L'analyse s'organise autour de quatre axes : l'autorité du magistrat, l'autorité en crise avec l'exemple des Fourches caudines, les exempla liés aux élections et les élections envisagées comme des récits sur les magistrats. Le premier chapitre («Magisterial 
authority and the politics of affection») explore la figure de la sévérité paternelle, à travers des personnages passés à la postérité, pour appréhender les conflits générationnels, y compris pour des magistrats. C'est le cas du tribun de la plèbe de 232, C. Flaminius, et de sa loi agraire. La patria potestas s'oppose alors à la sacrosainteté tribunicienne. La construction mémorielle est ici abordée sous l'angle des sources divergentes. Fabius Maximus (cos. 213) a pris la suite du commandement de son père en Apulie. Le célèbre Cunctator a alors décidé de le seconder en tant que légat. Le cœur du conflit est la contradiction qui existe entre l'imperium et la patria potestas. Deux autres exempla célèbres sont abordés: Brutus et Manlius Torquatus. Les différends générationnels sont poussés à leur paroxysme lors de la mise à mort de la descendance de ces magistrats pour maintenir l'éthique de la République et garantir la souveraineté de l'imperium.

Le chapitre suivant («Authority in crisis: the Caudine Forks») envisage le comportement consulaire. Les consuls vaincus aux Fourches Caudines, T. Veturius et Sp. Postumius, se substituent à l'État romain lors de la conclusion du traité de paix. L'attention est ensuite portée sur la persona consulaire, sa déconstruction après la bataille, puis sa reconstruction progressive après la victoire de Luceria. Le prestige consulaire est ainsi pleinement restauré.

4 Le troisième chapitre («Elections and the generation of exempla ») traite de l'archétype duuir militaris dans un contexte électoral avec plusieurs exemples. En 215, le consul suffect Q. Fabius Maximus Cunctator arrête les élections pour exhorter les électeurs à un vote décent. Cela va au-delà de la récurrente concurrence aristocratique, puisque nous sommes en pleine deuxième guerre punique. Il faut des magistrats "dignes " de l'imperium militiae. Plus tard L. Hostilius Mancinus n'hésita pas à exhiber des peintures du siège de Carthage en 146. Grâce à son prestige, il fut ensuite élu consul. Dans cette fabrique du uir militaris, le dénigrement des concurrents et de ses prédécesseurs est de bon ton, comme Marius lors de sa première campagne pour le consulat. Toutefois l'excellence militaire peut se retourner contre le commandant. Ainsi lorsque le père et l'oncle de Scipion l'Africain périrent en Hispanie en 212, c'est l'unus uir L. Marcius qui prend la tête de l'armée romaine pour la sauver. Il demande ensuite officiellement le titre de propraetor, mais le Sénat refuse car le mos n'avait pas été respecté.

D'autres exemples de candidats à une magistrature supérieure sont abordés dans le dernier chapitre («Elections as narratives of magistracy»). Toutefois, le cadre général est différent, puisqu'il s'agit d'un temps de paix. L'auteur reprend l'étude fort connue du Pro Murena de Cicéron avec le portrait du candidat idéal. Le chapitre explore plus particulièrement les interruptions du processus électoral pour des raisons multiples menant certains personnages à exercer une forte auctoritas.

Un épilogue, une bibliographie (p.178-192) et un index viennent clôturer ce court ouvrage qui ne prétend pas à l'exhaustivité. A. Lushkov propose un point de vue particulier sur le thème apparemment galvaudé des exempla, en faisant la part belle aux sources dont de nombreux passages sont donnés, y compris en latin, et commentés. Un des grands mérites de l'ouvrage s'avère être le commentaire précis et détaillé des sources qui sont confrontées pour dégager les variations dans l'exemplum. 


\section{AUTEUR}

CYRIELLE LANDREA

Laboratoire ANHIMA

cyrielle.landrea@orange.fr 